\title{
FENOLOGÍA DE E. globulus, E. nitens Y E. camaldulensis EN LA ZONA CENTRAL DE CHILE: ESTUDIO PRELIMINAR.
}

\author{
VERÓNICA LOEWE M (*)., CARLOS ALVEAR S (**) Y FRANCISCO SALINAS A. (***)
}

(*) Ingeniero Forestal, INFOR

(**) Médico Veterinario, Dr. Cs. Agr., INFOR

(***) Técnico Forestal, INFOR.

\section{RESUMEN}

Desde 1988 el Instituto Forestal se encuentra ejecutando un completo estudio sobre el mejoramiento genético del género Eucalyptus. Uno de los objetivos de este estudio es la instalación de un huerto semillero de polinización directa. Para tal efecto es necesario un completo conocimiento del comportamiento fenológico de especies, procedencias y familias.

Para conocer los diversos tópicos fenológicos se realizó un estudio preliminar en etapa de viverización en especies de $\mathbf{E}$ globulus, nitens y camaldulensis, en la temporada 1993 y 1994. fase previa a los estudio de terreno.

Junto con entregar los resultados de la toma de datos en las tres especies se anexan antecedentes Morfologicos, edad de floración, frenologia floral y fenofases del ciclo reproductivo. Se observa un desarrollo fenológico continuado, donde la liberación de semillas ocurre durante todo el año, presentando una mayor abundancia en el peniodo estival.

En la especie E globulus el estudio arrojó similitudes entre procedencias Victoria y Tasmania), diferenciándose sólo en su desarrollo fenológico en distintas etapas del seguimiento. (precocidad en procedencia Tasmania ).

El Eucalyptus nitens presenta una alta sensibilidad a los cambios climáticos lo que genera una alteración en su comportamiento Fenotogico. La liberación de semilla es inhibida en los meses invernales. Por el contrario en el cuatrimestre Noviembre - Febrero ocurre la mavor liberación de semillas. En cuanto al comportamiento entre procedencias y Nueva Gales del Sur . NSW y Victoria i, sus diferencias son minimas.

En E camaldulensis la produccion de semillas es prácticamente durante todo el año, al igual que la maduración de frutos.

Si bien el estudio es de carácter prelininar, en cierta medida presenta el comportamiento de las especies en la zona central de Chile, variando el potencial geográfico de las especies. Esto permite establecer parámetros de comparación. siendo enriquecido por mediciones de ensayos ubicados en zonas estratégicas de interés.

Cabe destacar que las tres especies presentan desarrollo floral durante todo el año: sin embargo, el comportamiento fenológico es variable de año a año. lo que refuerza la necesidad de ejecutar un seguimiento de al menos tres años en las distintas areas de crecimiento a fin de oblener una información precisa y confiable. 


\section{ABSTRACT}

Since 1988 the Instituto Forestal (Forestry Research Institute) is carrying out a study on the genetic improvement of the Eucalyptus genus. One of the objectives is to install a seed orchard of direct pollination, and therefore a previous knowledge of the floral behavior was required. including species provenances and families.

A preliminary study on nursery stages was carried out for $E$. globulus, $E$. nitens an $E$. camaldulensis, in the Summer seasons of 1993 and 1994 . The results indicate that seeding occurred in all seasons with a peak in the Summer. As there were variations in this behavior from year to year, a three-year monitoring has been recommended. 


\section{INTRODUCCIÓN}

Desde 1988 el Instituto Forestal se encuentra realizando un completo estudio sobre el género Eucalyptus, que considera la silvicultura. el manejo y el mejoramiento genético de las especies más promisorias del género. Para el estudio relativo al mejoramiento genético una de las etapas fundamentales es el conocimiento acabado del comportamiento fenológico de las especies. procedencias y familias de interés.

El comportamiento fenológico, es decir los cambios que presenta la floración con respecto al transcurso del tiempo, es uno de los aspectos de importancia a considerar la planificación y la instalación de un huerto semillero de polización directa. Si las familias consideradas en una cierta superficie florecen al mismo tiempo. tendrán iguales oportunidades de cruzarse entre sí. favoreciendo la panmixia. Conociendo entonces el comportamiento fenológico de diferentes procedencias y familias es posible ordenarlas espacialmente. de modo de reducir al minimo la endogamia.

Además, lo anterior permite planificar cuidadosamente las actividades de polinización controlada. necesarias en todo programa de mejoramiento genético.

El trabajo presentado a continuación corresponde a un estudio preliminar realizado en vivero. en la ciudad de Santiago. con tres especies (E. globulus. E. nitens y E. camaldulensis). durante los años 1993 y 1994. etapa previa a los estudios en terreno. actualmente en curso en ensayos de campo en diferentes regiones.

\section{ANTECEDENTES}

\section{Características Generales}

En la actividad forestal los productos son derivados del crecimiento vegetativo más que del crecimiento reproductivo de los árboles (frutos). Sin embargo, con la excepción de una minoria de especies que se reproducen vegetativamente en forma comercial, es necesario conocer y manejar la biología reproductiva de las especies forestales con el objetivo de regenerar los cultivos. Se trata de producir semilla en huertos manejados en forma óptima con respecto tanto a cantidad como a calidad genética y fisiológica (Sedgley y Griffin. 1989).

Dentro del género Eucalyptus existe gran diversidad de estructuras reproductivas de diferentes especies (tamaño. forma y color de las yemas florales, flores y frutos): estas caracteristicas, junto con otras, son heredables. y de hecho contribuyen a la definición de las especies (Boland et al. 1980). 
El género Eucalyptus presenta un sistema reproductivo con características de hermafroditismo, dicogamia, autoincompatibilidad y partenocarpia (Sedgley y Griffin. 1989).

Dentro de este género, las especies comerciales se concentran fundamentalmente en dos subgéneros, Symphyomyrtus y Monocalyptus, los que difieren en características tales como desarrollo del opérculo, anatomía del involucro de la semilla y distribución de los óvulos y ovuloides (Hodgson, 1976a).

El opérculo es formado por la fusión de los pétalos. En las especies del subgénero Monocalyptus éste es simple, mientras que en los subgéneros Symphyomyrtus y Corymbia es una estructura doble. Cuando el opérculo es doble, el exterior puede caer al inicio del desarrollo de la yema floral. como ocurre en E. camaldulensis; cerca de la floración. como en E. cosmophylla: o pueden caer ambos opérculos juntos en el momento de la floración. como en E. polycarpa (Op. cit.).

Dentro del subgénero Monocalyptus, generalmente las semillas son más uniformes que en otros subgéneros en cuanto a tamaño. forma y color (son de color café o negro en forma más frecuente): generalmente no se encuentra paráfisis subulada. Por el contrario. en el subgénero Symphyomyrtus la semilla puede ser cuboidal, piramidal, eliptica. de color blancuzco, gris, amarillo. rojo. café o negro (Boland et al.. 1980).

\section{Morfología Floral}

Las flores de los eucaliptos no presentan pétalos típicos, y el color está dado por los estambres. Internamente la yema floral muestra la estructura básica de una for bisexual, con un estaminóforo que sostiene los estambres. y cl ovario. estilo y estigma. Cuando el opérculo se desprende las anteras poseen polen maduro, pero el estigma normalmente no esta receptivo hasta unos días después: esta secuencia impide la autopolinización de la flor (Urrutia. 1992).

\section{Eucalyptus globulus}

La especie presenta inflorescencias unifloras. siendo las flores solitarias. auxiliares, sin pedicelo, con receptáculo rugoso. cuadrangular, de 20-25 mm; opérculos en forma de sombrero, glaucos (Op cit.).

Los frutos son grandes $(2.5 \mathrm{~cm}$ de diámetro). solitarios. no pedicelados, glaucos, semipiramidales, cuyos receptáculos terminan en un gran reborde en la unión con el disco calicinal; presentan cuatro valvas. incluidas o rasantes. En general los frutos están maduros cuando se tornan color café. duros y leñosos. 


\section{Eucalyptus camaldulensis}

El E. camaldulensis presenta una inflorescencia axilar, no ramificada, de 7 a 11 (raramente 13) flores, pedúnculos esbeltos, angulares de 0,4 a $2,5 \mathrm{~cm}$ de longitud. Yema pedicelada (con pedicelos a veces hasta $1 \mathrm{~cm}$ de largo) de $0,5-1,0$ por $0,4-0,6$ $\mathrm{cm}$, con presencia de escamas. El opérculo es fuertemente aguzado, los estambres inflexos, todos fértiles; anteras versátiles. abiertas con ranuras longitudinales, flores blancas. El período de floración en Australia es entre Julio y Febrero. El fruto pedicelado, hemisférico (ovoide incluyendo el disco), entre $0,3-0,7$ por $0,4-1,0 \mathrm{~cm}$, de bordes gruesos, disco amplio, ascendente; valvas en número de 4 (raramente entre 3 y 5), fuertemente exertas; semilla amarilla, forma cuboide, con ángulos y caras suaves (Brooker y Kleinig, 1990).

\section{Eucalyptus nitens}

Las inflorescencias de E. nitens son axilares y simples con umbelas de unas 7 flores, siendo cada una de ellas de unos $7 \times 3 \mathrm{~mm}$. Las yemas de los primordios se hacen visibles cerca de 12 meses antes de la floración, y las semillas maduran cerca de un año después de la polinización (Tibbits, 1989).

Con respecto al desarrollo del polen, Gore et al. (1990) examinaron el crecimiento de tubos polínicos de E. globulus y E. nitens en estilos de E. globulus, para aclarar el problema de la barrera unilateral existente para la hibridación; se concluyó que ésta se debe a una barrera estructural por el límite natural de crecimiento del tubo polínico respecto a la longitud del estilo (en el día 28 , cuando el estilo cae, el tubo polínico de $\mathbf{E}$. nitens sólo ha crecido $6 \mathrm{~mm}$, siendo el primero de $9-10 \mathrm{~mm}$ de longitud). Esta barrera se presenta antes de la fertilización, y no es debida a una inhibición de la penetración inicial o de la germinación del grano de polen.

El mismo fenómeno fue observado in vitro, donde los tubos polínicos de $\mathbf{E}$. nitens crecen mucho menos que los de E. globulus: también en otras especies (E. ovata, E. urnigera, E. gunni) existe una alta correlación entre la longitud del estilo y la longitud del tubo polínico germinado in vitro.

Al respecto. existen barreras abocadas a impedir la polinización (cleistogamia. posición de los estambres con respecto al estigma): después de la polinización la fertilización puede ser alterada por varias causas, entre las cuales podemos citar:

- autoinfertilidad (poca semilla fértil):

- incompatibilidad de germinación del polen;

- incompatibilidad de crecimiento del tubo polínico. 
Además se ha visto que existe la fertilización selectiva. que se traduce en que al mezclarse los pólenes se ven favorecidas las cruzas y no la autopolinización.

Aún después de la fertilización se puede producir el aborto del embrión o la inviabilidad de la semilla. fenómenos todos que miran a impedir o dificultar la autogamia. la que se estima mediante el uso de marcadores genéticos (Hodgson, 1976b)

\section{Edad de Floración}

No existen muchos antecedentes sobre las edades a las que las diferentes especies alcanzan la madurez reproductiva. salvo algunos casos como E. grandis (2-3 años). E. leucoxylon ( 2 años) y E. woodwardii (antes de un año).

En todo caso los eucaliptos entran en floración en edades tempranas. existiendo variaciones para una misma especie según altitud. ubicación geográfica y condiciones climáticas.

La inducción floral depende de factores tales como:

- juvenilidad:

- dormancia.

- factores ambientales (altitud. clima):

- desarrollo floral: y

- reguladores de crecimiento.

Entre los últimos influven en la floración sustancias quimicas tales como el chlormequat. el alar. el TIBA. el paclobutrazol. las giberelinas (inducen floración en muchas gimnospermas). el ácido giberélico (la inhibe) y las citoquininas (pueden promover la iniciación floral).

Algunas especies como E. nitens y E. globulus producen semillas en forma irregular (son "añeros"): en E. regnans la floración en los años buenos puede llegar a ser 25-65 veces mavor que en los años pobres (Ashton. 1975b).

Con respecto a los factores ambientales. en líneas generales a mayor altitud y a menores temperaturas la floración se prolonga en cl tiempo.

Con respecto al crecimiento vegetativo. en general en los eucaliptos existe una profusa ramificación estacional de ramas axilares, pero relativamente pocas de ellas (25) compiten con la rama apical durante los primeros años de crecimiento (es decir. la dominancia apical es elevada): las yemas axilares que permanecen $5-7 \mathrm{~cm}$ bajo la yema terminal pueden ocasionalmente crecer más rápido que el brote principal. En todo caso 
existe una gran variación en la tasa de crecimiento entre distintas plantas. y también entre las ramas de una misma planta (Ashton, 1975a).

La curva de crecimiento estacional es sigmoidea, a pesar de presentarse variaciones de año en año.

El crecimiento invernal varía con la altitud; en inviernos suaves pueden haber elongaciones de hasta $2 \mathrm{~mm} / \mathrm{mes}$, y no se producen nuevas hojas.

Por otra parte el patrón de crecimiento estacional de árboles adultos y de formas juveniles puede diferir considerablemente.

Una temperatura media de $5,0-7,5^{\circ} \mathrm{C}$ es el límite de crecimiento activo. A su vez el crecimiento se detiene cuando la temperatura mínima se mantiene a $-2{ }^{\circ} \mathrm{C}$ por una 0 dos semanas, y se inicia cuando la temperatura se mantiene $11-12$ dias a $12.5^{\circ} \mathrm{C}$; o cuando se mantiene $6-7$ dias a $15^{\circ} \mathrm{C}$; o por más de $2-3$ dias a unos $17.5^{\circ} \mathrm{C}$.

Con temperaturas altas en invierno el crecimiento se activa de inmediato, pero a tasas de sólo una cuarta parte de las de primavera debido a la luminosidad inferior. El crecimiento también está influenciado por la disponibilidad de agua.

Cabe notar que los factores que causan la dormancia pueden no ser los mismos que inician el crecimiento.

Se ha visto que una mayor duración del día no afecta la tasa de crecimiento. En los eucaliptos los dias cortos no inducen dormancia. pero con temperaturas adecuadas y una mayor duración del dia hay un mayor crecimiento (Op cit.).

En un estudio realizado en Italia por Valenziano y Scaramuzzi (1967) se observó que E. camaldulensis florece entre julio y agosto (verano europeo). y que E. viminalis lo hace entre noviembre y febrero (otoño e invierno europeo). Sin embargo, analizando el crecimiento en diámetro de los fustes constataron que el comportamiento es similar en las dos especies. iniciándose a principios de marzo y disminuyendo paulatinamente hasta anularse en junio: después de un receso estival el crecimiento recomienza en julio para detenerse en diciembre. El reposo invernal obedeceria a las bajas temperaturas más que a un verdadero período de reposo. ya que no conlleva estructuras preparatorias de defensa. sino que solamente se suspende el crecimiento. El reposo estival respondería a una fase de mayor intensidad de foliación, con una consiguiente competencia nutricional; en otros casos también se verifica debido a stress hídrico.

La carencia de receso invernal propiamente tal también fue observada en este estudio tanto en E. nitens. E. camaldulensis como en E. globulus.

Las especies del género Eucalyptus muestran gran variación en el periodo de floración. A pesar de que el máximo puede ser regular. algunas especies llegan a florecer intermitentemente durante gran parte del año. aunque también pueden encontrarse variaciones entre un rodal y otro (Griffin. 1980). 
El periodo de floración puede ser identificado por medio del conteo de los diferentes componentes floreales colectados en trampas ubicadas bajo los árboles. o por medio de observaciones periódicas (generalmente mensuales).

Tibbits (1989) en cuatro años de estudio observó que la época de floración de E. nitens es muy diferente de año en año.

La mayoria de los árboles empiezan y terminan la floración dentro de un arco de 3-4 semanas. Sin embargo. el margen de época de floración dentro de una procedencia es a menudo uniforme. El mismo autor sugiere la existencia de un fuerte control genético sobre la floración, al menos a nivel de la población.

También Griffin (1980) considera que existe control genético sobre las características de la floración: se ha observado variación genética en la época de floración en individuos de 6 años.

Cabe notar que dentro de una misma procedencia existen diferencias en los tiempos de floración entre los individuos de forma juvenil y adulta. Asimismo. las semillas de árboles juveniles maduran cerca de 2 meses antes que las de formas adultas (Tibbits, 1989). Coincide Ashton (1975b). quien indica que en un mismo sitio los árboles de mayor edad tienden a florecer más tarde que los jóvenes.

Por otra parte los árboles adultos presentan yemas florales más redondeadas que las juveniles: los pedúnculos son más largos y las cápsulas presentan valvas más exertas.

Dentro de un individuo se observa que el período de floración depende del número de flores / umbela. Las inflorescencias con muchas flores tienden a abrir durante un periodo más largo que aquellas con pocas flores. Las subramas dentro de una rama tienden a ser más sincronizadas con respecto a otras ramas (Griffin. 1980). El periodo de floración de una rama dura la mitad del periodo total del árbol.

Las diferencias existentes entre árboles en duración y máximo de floración puede llevar a problemas de manejo. particularmente si se establecen huertos semilleros con individuos que se han desarrollado en ambientes diferentes.

\section{Fenología Floral}

Las observaciones fenológicas son de gran valor en la interpretación de la estructura de las poblaciones naturales para el mejorador. quien necesita asegurar que los productos de su programa de selección sean exitosos (polinizaciones controladas) bajo condiciones de huertos semilleros (Op cit.).

La copa de un árbol puede ser considerada como una población heterogénea de ramas y hojas. desigualmente sujetas a los factores ambientales. Por esto es importante decidir si los estudios fenológicos se deben realizar en toda la copa o solamente en algunas ramas: ésta última opción podria no ser una aproximación correcta a los 
eventos de todo el dosel. Este es un tópico importante, ya que las mediciones en terreno son dificultosas y caras.

En todo caso el mismo autor afirma que el tamaño de la muestra no es importante a la hora de determinar las características de la floración, pues en árboles vecinos ésta tiende a sincronizarse.

Oliveira et al. (1993) indican que las áreas de la copa que reciben mayor radiación tienen mayor crecimiento y producen más biomasa.

La intensidad de floración es independiente del tamaño del árbol, pero hay una tendencia para los árboles con una gran copa cargada de yemas a florecer por un período de tiempo más prolongado que aquellos con una copa ligera (Griffin. 1980).

En un estudio realizado en India por Venkatesh y Sharma (1975) se constató que todas las especies estudiadas presentaban solamente un comportamiento fenológico. salvo E. camaldulensis, cuyas procedencias del norte y del sur presentaron comportamientos diferentes (tal vez debido a diferencias fisiológicas).

La época de floración de $\mathbf{E}$. globulus spp globulus se produce entre los meses de Septiembre a Diciembre, y la de cosecha de semillas entre Diciembre - Febrero (Urrutia. 1992).

El E. nitens en Tasmania florece en verano (Tibbits, 1989).

Como ya se ha mencionado con respecto a la semilla producida, especies tales como E. camaldulensis, E. grandis $\mathbf{y}$ E. saligna generalmente presentan cosechas abundantes cada 2-3 años; en E. regnans el período es cada 2-4 años. Estos antecedentes son de importancia al momento de planificar la cosecha y producción anual de plantas.

\section{METODOLOGÍA}

El estudio consideró la medición semanal durante un año de 64 individuos de $\mathbf{E}$. globulus: 41 de E. nitens y 12 de E. camaldulensis, de una altura media de $1.65 \mathrm{~m}$ mantenidos en bolsas plásticas de $20 \mathrm{~cm}$ de diámetro. Para cada especie se consideraron diferentes procedencias de interés. Sin embargo, para efectos del análisis estadístico algunos individuos fueron eliminados debido a la presencia de abortos.

El formulario utilizado consideró información tal como: $\mathrm{N}^{\mathrm{D}} \mathrm{y}$ fecha de control. especie. controlador. etapa del ciclo vegetativo y del ciclo reproductivo. Las mediciones se realizaron mediante una escala fenológica determinada en estudios previos y con la asistencia de expertos australianos. la que considera 10 fenofases del ciclo reproductivo 
(Cuadro $N^{\circ} 1$ ), y 2 del ciclo vegetativo (fase de crecimiento vegetativo y fase de receso vegetativo). apta para las especies en estudio.

\title{
En las Figuras $\mathrm{N}^{\circ} 1$ a $\mathrm{N}^{\circ} 3$, se destacan las primeras fases en diferentes especies de Eucalyptus.
}

\author{
Cuadro $\mathrm{N}^{\circ} 1$. \\ FENOFASES DEL CICLO REPRODICTIVO.
}

\begin{tabular}{|c|c|}
\hline FENOFASE & ESTADO DEL INDIVIDUO \\
\hline 0 & $\begin{array}{l}\text { Se presenta una bráctea que envuelve a la yema única o a la inforescencia: es válida para todas } \\
\text { las especies del género, aunque se trata de una fase muy breve. Generalmente E. globulus ssp } \\
\text { globulus presenta una yema, pero no es asi siempre. presentando algunas procedencias 2-3 } \\
\text { yemas múltiples (por ejemplo en West Coast. Flinders Islands. King Island). }\end{array}$ \\
\hline 1 & Yemas Florales: La bráctea (verde) se oscurece, seca y cae. apareciendo las yemas. \\
\hline 2 & $\begin{array}{l}\text { Yemas Hinchadas: Las yemas se presentan engrosadas. En el caso de E. globulus y E. nitens } \\
\text { en esta fase se pierde el opérculo exterior (glauco). En el caso de F. camaldulensis esta fase se } \\
\text { caracteriza por el aumento de tamaño y por el color rojizo en la zona de unión entre el opérculo } \\
\text { y la capsula. y por las manchas rojizas que aparecen en el opérculo mismo. el cual se presenta } \\
\text { alargado y engrosado en su prolongación. }\end{array}$ \\
\hline 3 & $\begin{array}{l}\text { Apertura del Opérculo: El opérculo empieza a abrirse. l os estambres se encuentran doblados } \\
\text { sobre si mismos en el interior de la cápsula. }\end{array}$ \\
\hline 4 & $\begin{array}{l}\text { Floración: La flor se encuentra en antesis. Algunos dias más tarde el estigma se encuentra } \\
\text { receptivo y brillante, debido a la acción de las sustancias segregadas para favorecer la } \\
\text { polinización (E. globulus 6-8 dias. E. nitens 6-10 dias más tarde). }\end{array}$ \\
\hline 5 & $\begin{array}{l}\text { Caida de los Estambres: } 1 \text { os estambres se marchitan y caen. En esta fase el estilo se puede } \\
\text { observar en tres estados: verde, café (marchito). o ausente. habiéndose desprendido. }\end{array}$ \\
\hline 6 & Fruto Inmaduro: Formación y crecimiento del fruto. que se observa de color verde. \\
\hline 7 & $\begin{array}{l}\text { Fruto Maduro: Los frutos alcanzan un aspecto mas leñoso. F.n el caso de E. camaldulensis y } \\
\text { E. nitens el fruto adquiere un color rojizo. }\end{array}$ \\
\hline 8 & Caida de Semillas: Las semillas son liheradas. \\
\hline 9 & Caida del fruto: Los frutos se desprenden y caen. \\
\hline
\end{tabular}




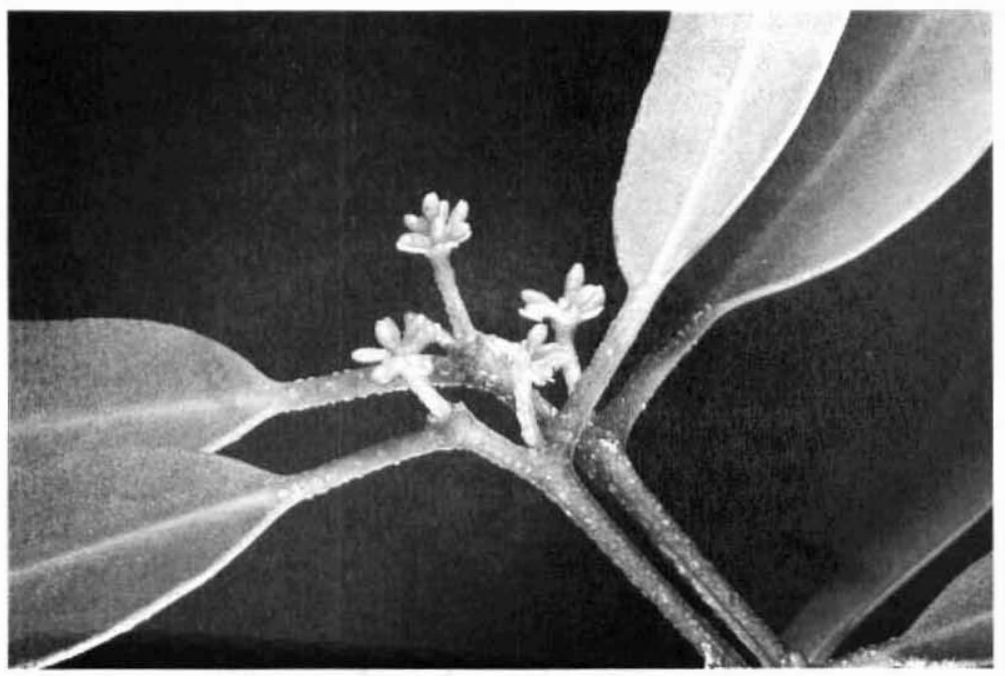

Figura $N^{\circ}$ 1: FASE DE YEMA FI,ORAL (1) EN E nisens.

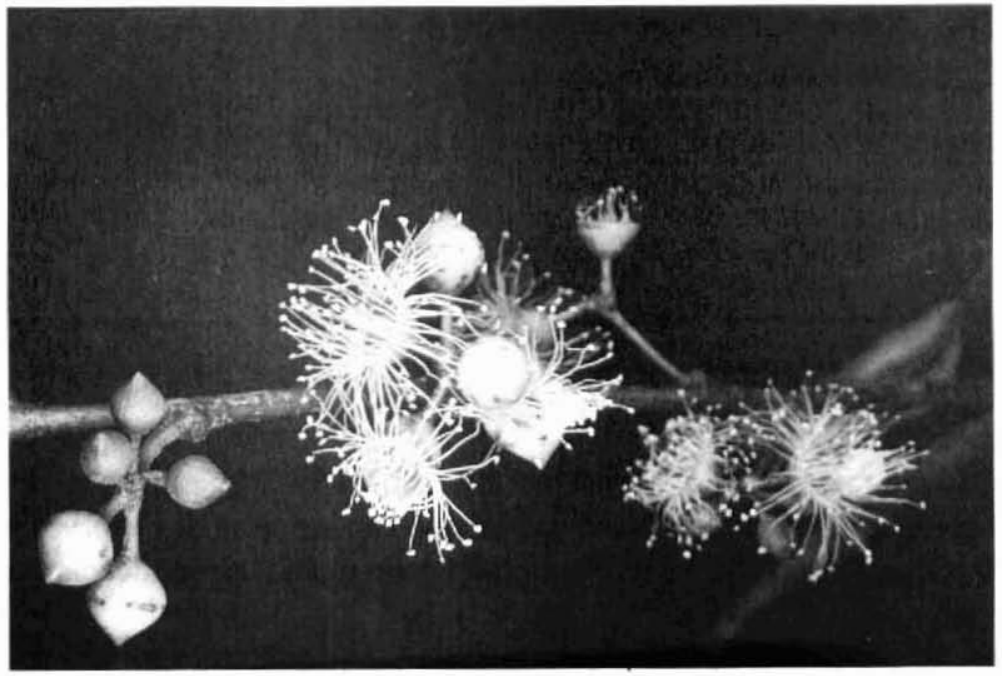

Figura $N^{\circ}$ 2: FASE DE YEMA HINCHADA (3) EN E. globulus. 


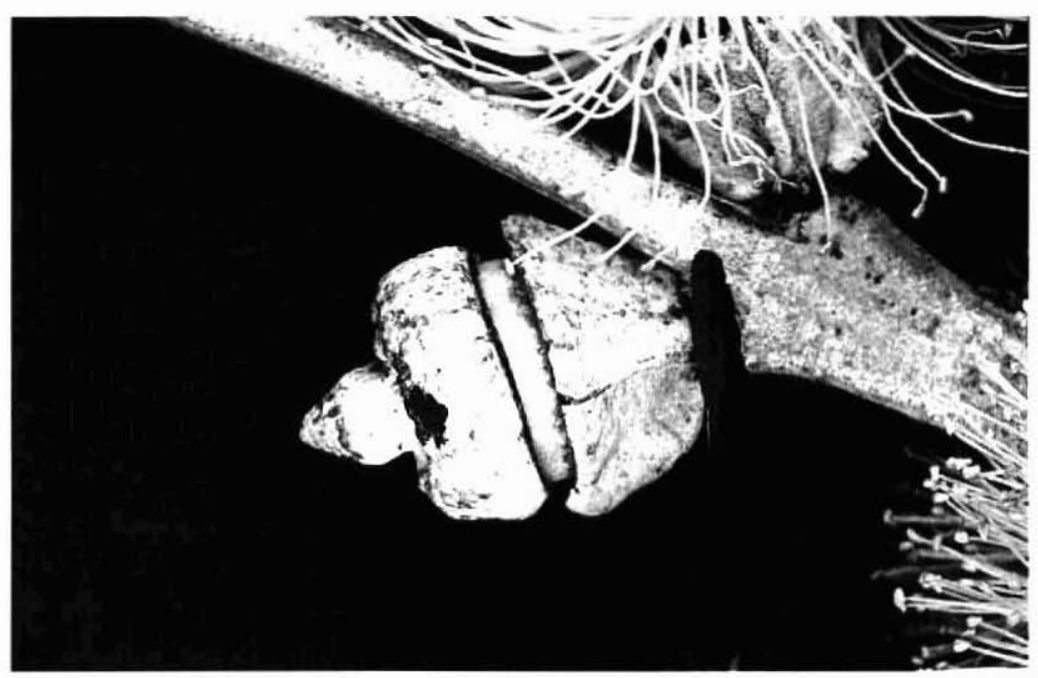

Figura $N^{\circ}$ 3: FASES QIE INCLIYEN DESDE YEMA FLORAL (2) A FRUTO INMADURO, EN E. nirens.

Posteriormente los datos fueron procesados mediante un análisis grupal "cluster" para reunir los individuos en las categorias de precoces. intermedios y tardíos. y analizar el comportamiento de cada especie.

Para determinar el porcentaje correspondiente a cada fenofase se evaluó toda la copa del árbol. estimando cualitativamente dicho parámetro.

\section{RESULTADOS}

\section{E. globulus}

De las observaciones realizadas se concluye que con respecto al ciclo vegetativo la especie se mantiene activa en crecimiento durante todo el año. sin evidenciar un receso propiamente tal.

Con respecto al ciclo reproductivo. destaca el hecho de que en la localidad estudiada la floración se detiene solamente en un corto período a principios de invierno, con máximos en primavera y verano (Figura $\mathrm{N}^{\circ} 5 \mathrm{~b}$.). La liberación de las semillas ocurre durante todo el año, con un máximo en verano debido a la apertura por calor de las cápsulas.

La producción de nuevas yemas se produce tanto en primavera como otoño. 
El estado fenológico de E. globulus a través del año muestra una gran variabilidad, atribuible a una condición individual de cada árbol, ya que se observan individuos que mantienen un estado fenológico relativamente constante durante todo el año (fruto maduro) y el resto de los estados en períodos muy cortos. El comportamiento fenológico de $\mathbf{E}$. globulus se entrega en el Figura $\mathrm{N}^{\circ} 4$; además se grafican las fases de apertura del opérculo (Figura $\mathrm{N}^{\circ} 4 \mathrm{a}$.), de floración (Figura $\mathrm{N}^{\circ} 4 \mathrm{~b}$.) y de caída de semillas (Figura $\mathrm{N}^{\circ}$ 4c.), respectivamente.

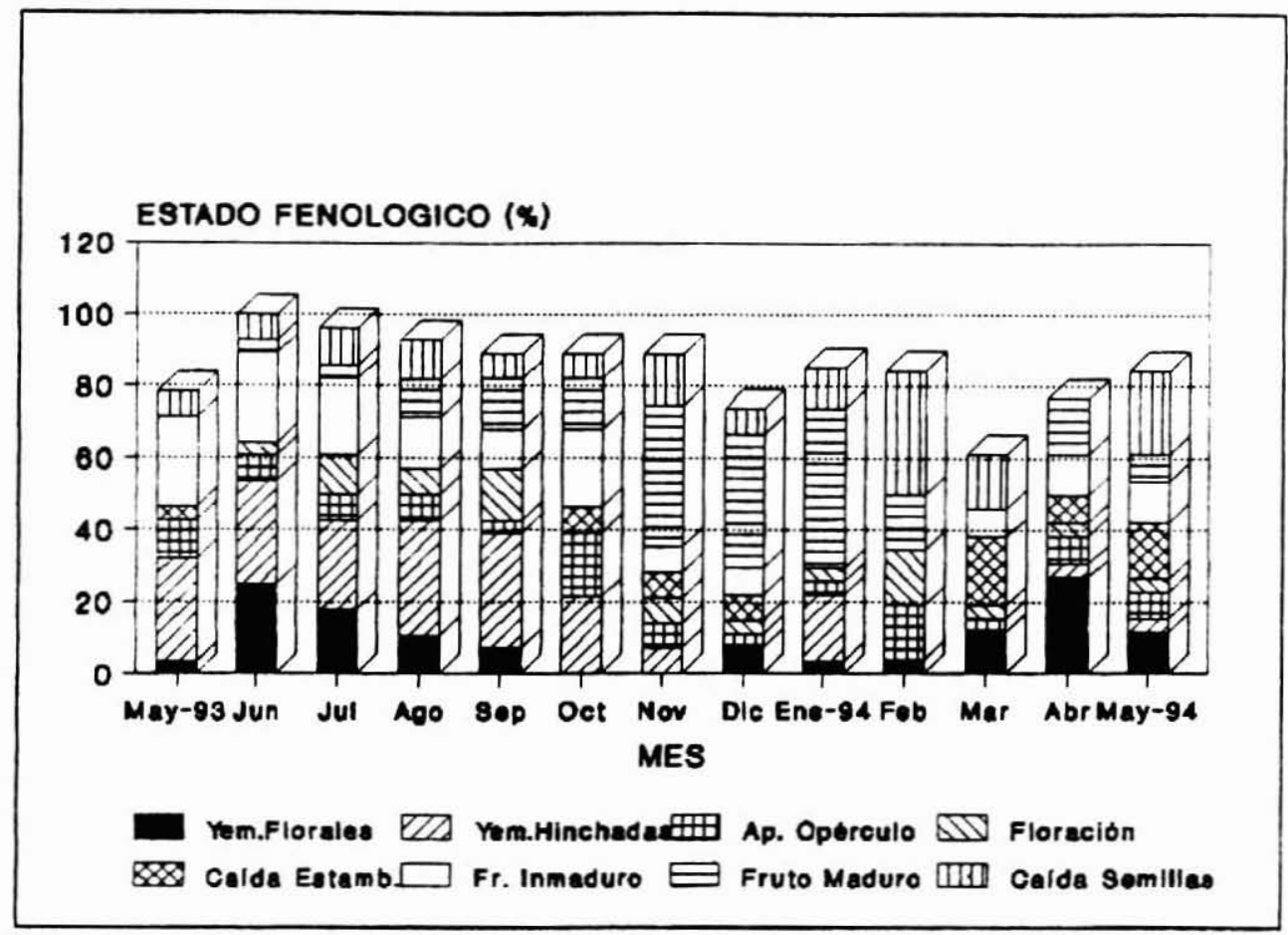

Figura No 4. COMPORTAMIENTO FENOLÓGICO DE E. globulus.

En general el comportamiento entre procedencias (Victoria versus Tasmania) fuc muy semejante, no existiendo diferencias significativas: esto se deberia principalmente a la variabilidad observada (margen de las observaciones), determinándose tendencias mensuales donde las procedencias de Tasmania presentan mayoritariamente un estado fenológico más avanzado. entre los meses de mayo 1993 hasta la primera quincena de enero 1994, situación que se minimiza desde la segunda quincena de febrero hasta mayo de 1994 (Cuadro $N^{\circ}$ 2). 
Diferencias significativas se observaron sólo en los meses de mayo a julio $(\mathrm{p}<0.05)$ tanto en el año 1993 como en 1994, destacando la precocidad de las procedencias de Tasmania en 1993, como se observa en el Cuadro $N^{\circ} 2$, ya que se encontraban en promedio entre la fase 4 (floración) y 5 (Caida de los estambres); en cambio, las procedencias de Victoria se encontraban entre las fases 2 (Yemas hinchadas) y 3 (Apertura del opérculo). En el año 1994 (abril y mayo) fueron las procedencias de Victoria las más precoces.

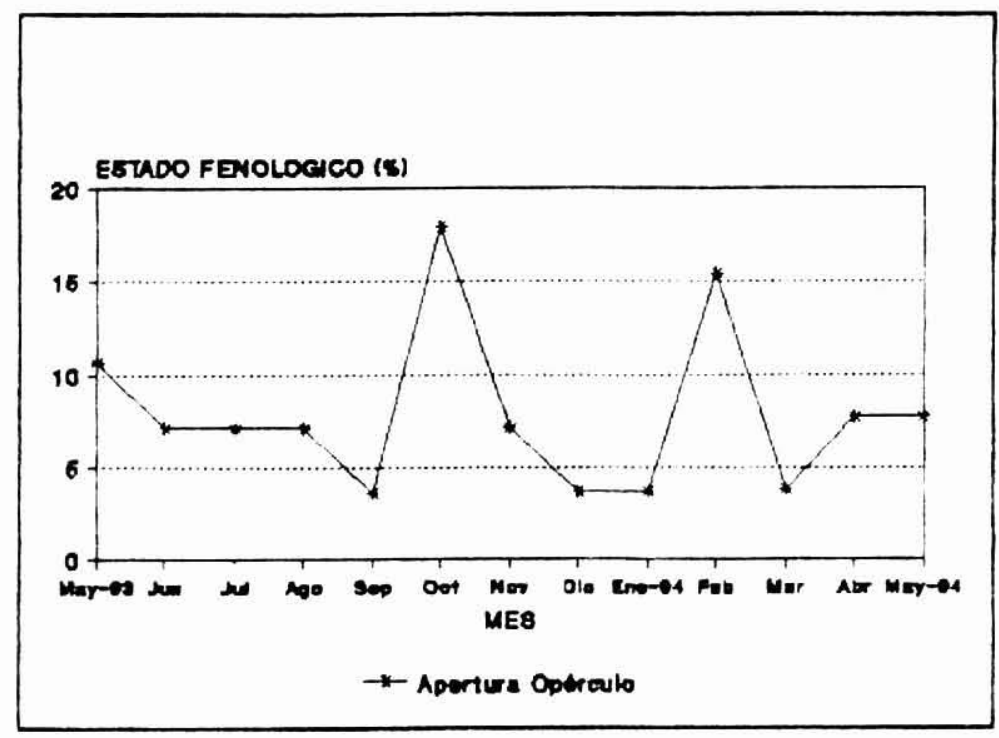

Figura $N^{\circ} 4$ a. APERTURA DEI, OPERÁCII O EN E. globulus 


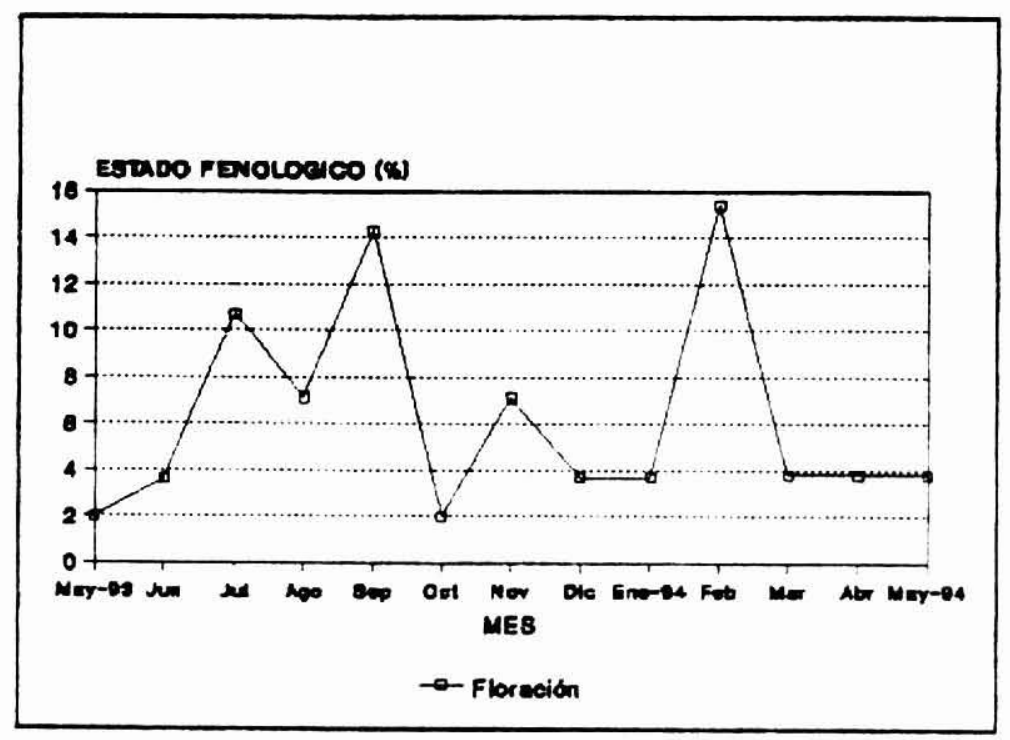

Figura $\mathrm{N}^{\circ} 4$ b. FLORACIÓN EN E. globulus

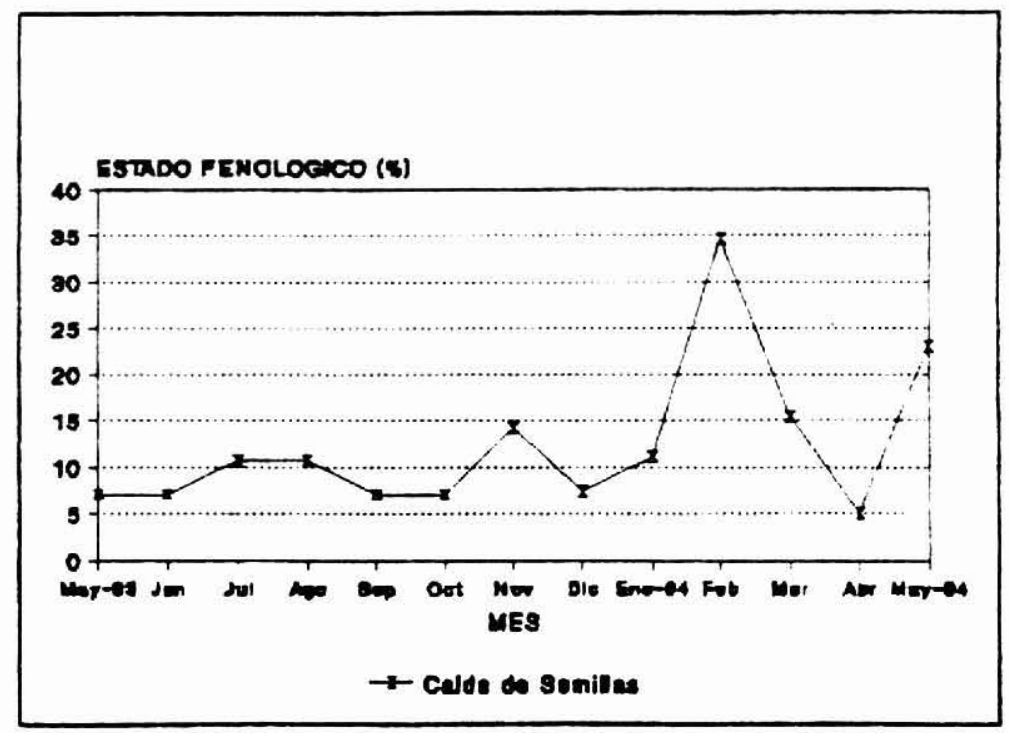

Figura $N^{0} 4$ c. CAIDA DE SEMILLA EN E. globulus 


\section{Cuadro $\mathrm{N}^{\circ} 2$.}

PROMEDIOS MENSUALES DE LOS ESTADOS FENOLÓGICOS DE PROCEDENCIAS DE Eucalyptus globulus., AÑO 1993

\begin{tabular}{|c|c|c|c|c|c|c|c|c|}
\hline \multirow[b]{2}{*}{ PROCED } & \multicolumn{8}{|c|}{ MESES } \\
\hline & $\begin{array}{l}\text { MAYO } \\
\mu \pm \text { DE }\end{array}$ & $\begin{array}{l}\text { JUNIO } \\
\mu \pm D E\end{array}$ & $\begin{array}{l}J U L I O \\
\mu \pm \text { DE }\end{array}$ & $\begin{array}{l}\text { AGOSTO } \\
\mu \pm D E\end{array}$ & $\begin{array}{c}\text { SEPT. } \\
\mu \pm \text { DE }\end{array}$ & $\begin{array}{l}\text { OCTUB. } \\
\mu \pm D E\end{array}$ & $\begin{array}{c}\text { NOV } \\
\mu \pm D E\end{array}$ & $\begin{array}{c}\text { DIC } \\
\mu \pm \text { DE }\end{array}$ \\
\hline VICTORIA & $\begin{array}{l}2,12,1^{6} \\
(0-6)\end{array}$ & $\begin{array}{l}2,62,0^{6} \\
(1-7)\end{array}$ & $\begin{array}{l}3,22,4^{b} \\
(1-9)\end{array}$ & $\begin{array}{l}3,62,8 \\
(1-9)\end{array}$ & $\begin{array}{l}3,92,8 \\
(1-9)\end{array}$ & $\begin{array}{l}4,42,7 \\
(1-9)\end{array}$ & $\begin{array}{l}5,72,5 \\
(2-9)\end{array}$ & $\begin{array}{l}5,12,5 \\
(1-9)\end{array}$ \\
\hline TASMANLA & $\begin{array}{l}4,72,5 \\
(1-8)\end{array}$ & $\begin{array}{l}4,82,4^{\circ} \\
(1-8)\end{array}$ & $\begin{array}{l}5,22,5^{\circ} \\
(2 \cdot 9)\end{array}$ & $\begin{array}{l}5,42,5 \\
(2-9)\end{array}$ & $\begin{array}{l}5,52,4 \\
(2-9)\end{array}$ & $\begin{array}{l}5,92,2 \\
(2-9)\end{array}$ & $\begin{array}{l}6,61,3 \\
(4-9)\end{array}$ & $\begin{array}{l}6,62.2 \\
(0-9)\end{array}$ \\
\hline PROMEDIO & $3,22,6$ & $3,62,4$ & $4,02,6$ & $4,42,8$ & $4,62,7$ & $5,02,6$ & $6,12,1$ & $5,82,4$ \\
\hline
\end{tabular}

a.b: letras diferentes en una misma columna determinan diferencias significativas $(p<0.05)$.

\section{Cuadro $\mathrm{N}^{\circ} 3$.}

PROMEDIOS MENSUALES DE LOS ESTADOS FENOLÓGICOS DE PROCEDENCIAS DE Eucalypeus globulus., AÑO 1994

\begin{tabular}{|c|c|c|c|c|c|}
\hline & \multicolumn{5}{|c|}{ MESES } \\
\hline PROCEDFNCIAS & $\begin{array}{c}\text { ENERO } \\
\mu \pm \mathrm{DE}\end{array}$ & $\begin{array}{c}\text { FEBRERO } \\
\mu \pm \mathrm{DE}\end{array}$ & $\begin{array}{c}\text { MARZO } \\
\mu \pm \mathrm{DE}\end{array}$ & $\begin{array}{c}\text { ABRIL } \\
\mu \pm \mathrm{DE}\end{array}$ & $\begin{array}{c}\text { MAYO } \\
\mu \pm \text { DE }\end{array}$ \\
\hline VICTORIA & 5.12 .9 & $5,82.5$ & $5,42.5$ & $4.42 .8^{\mathrm{a}}$ & $6,12.6^{\mathrm{a}}$ \\
& $(1-9)$ & $(3-9)$ & $(1-9)$ & $(3-9)$ & $(0-9)$ \\
& $6,32.2$ & 5.83 .3 & 6.33 .4 & $2,22.1^{\mathrm{b}}$ & $2.72 .6^{\mathrm{b}}$ \\
TASMANIA & $(0-9)$ & $(0-9)$ & $(0.9)$ & $(0-7)$ & $(0-7)$ \\
\hline PROMEDIOS & $5,62,7$ & 5.82 .8 & 5.82 .9 & 3.52 .7 & 4.63 .0 \\
\hline
\end{tabular}

a,b: letras diferentes en una misma columna determinan diferencias significativas $(p<0.05)$.

\section{E. nitens}

Esta especie respecto al ciclo vegetativo, también se mantiene activa durante todo el año, al igual que E. globulus.

El estado fenológico de E. nitens se muestra en el Figura $\mathrm{N}^{\circ} 5$. Con respecto al ciclo reproductivo se observó que la formación de yemas se produce principalmente en verano; la floración se arrastra desde el verano hasta la primavera siguiente (Figura $\mathrm{N}^{\circ}$ $5 b)$, siendo levemente más tardia que en $\mathbf{E}$. globulus. La liberación de semillas ocurre prácticamente durante todo el año, salvo en periodos muy fríos, con un máximo entre los meses de noviembre a febrero, debido a las condiciones térmicas (Figura $\mathrm{N}^{\circ} 5 \mathrm{c}$ ).

La especie demuestra ser muy sensible a los cambios climáticos. lo que determina en gran parte su comportamiento fenológico. 
Se observó que la especie conserva por largos periodos los frutos tanto en estado maduro como inmaduro, los que repentinamente pasan al estado siguiente.

El comportamiento fenológico en esta especie demostró ser menos variable que en E. globulus, debido por una parte al menor número de observaciones, y por otra a una condición de mayor estabilidad de la especie (Cuadro $\mathrm{N}^{\circ} 3$ ).

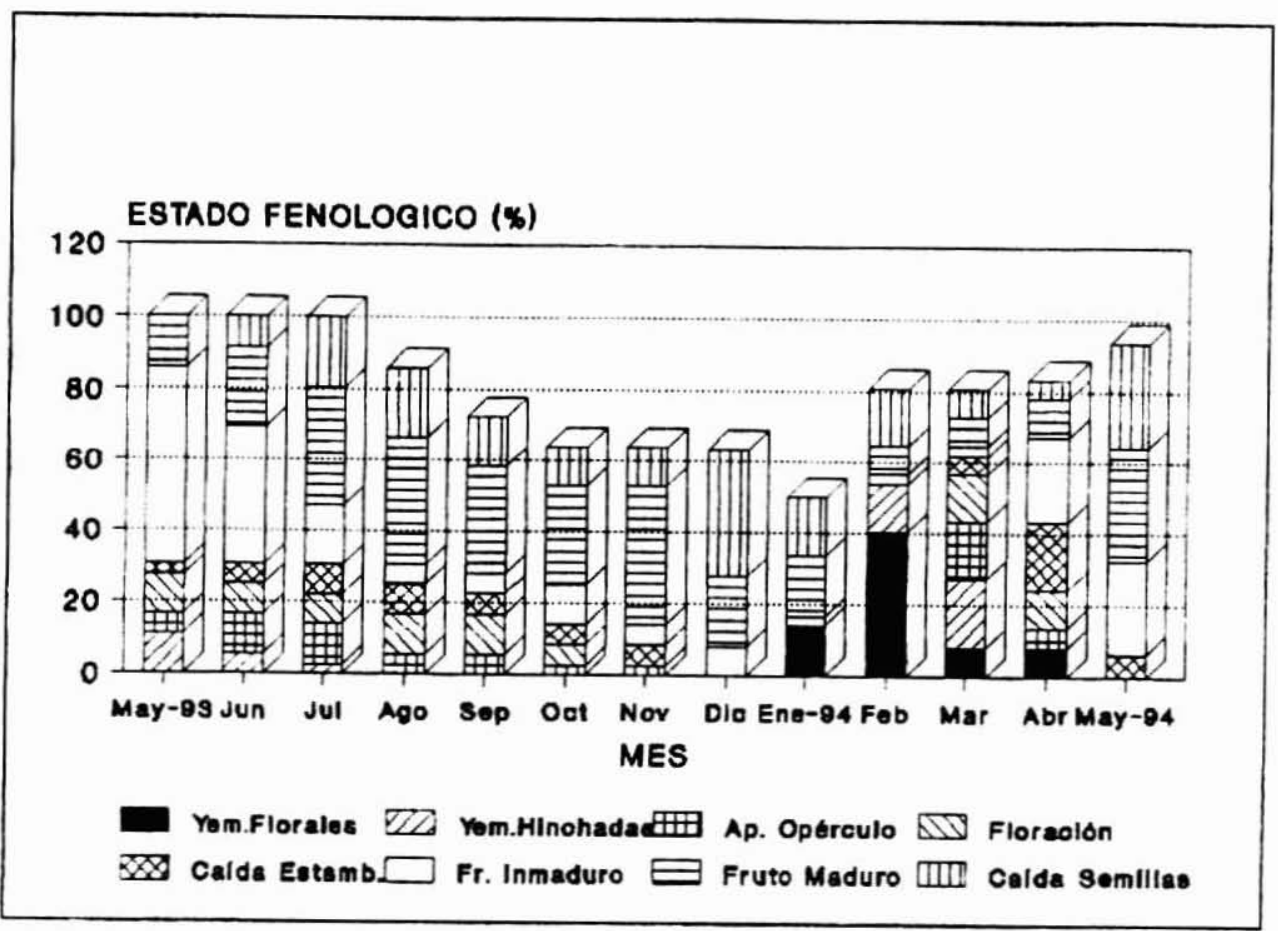

Figura $\mathrm{N}^{\circ}$ 5. COMPORTAMIENTO FENOLÓGICO E. nirens

El comportamiento mensual entre las procedencias de E. nitens (Nueva Gales del Sur - NSW y Victoria) durante el año fue semejante, no encontrándose diferencias significativas entre ambas procedencias $(p>0.05$ ). Las procedencias originarias de NSW durante los meses de mavo a diciembre de 1993 mostraron un estado fenológico más precoz que las originarias de Victoria (Cuadro $\mathrm{N}^{\circ} 3$ ), situación que se invierte en el verano 1994 hasta mayo del mismo año. de modo similar a lo descrito para E. globulus. 
Sólo en la primera quincena del mes de enero de 1994 se encontraron diferencias significativas entre las procedencias $(p<0.05)$ ya que las de NSW estaban iniciando la fase 3 (apertura del opérculo) mientras que las de Victoria se encontraban en la fase 6 (Fruto Inmaduro). Además, la procedencia de NSW fue bastante uniforme entre septiembre de 1993 a Enero de 1994. ya que todos se encontraron en la fase de fruto maduro (7). mientras que las procedencias de Victoria. en el mismo período. fueron mucho más variables.

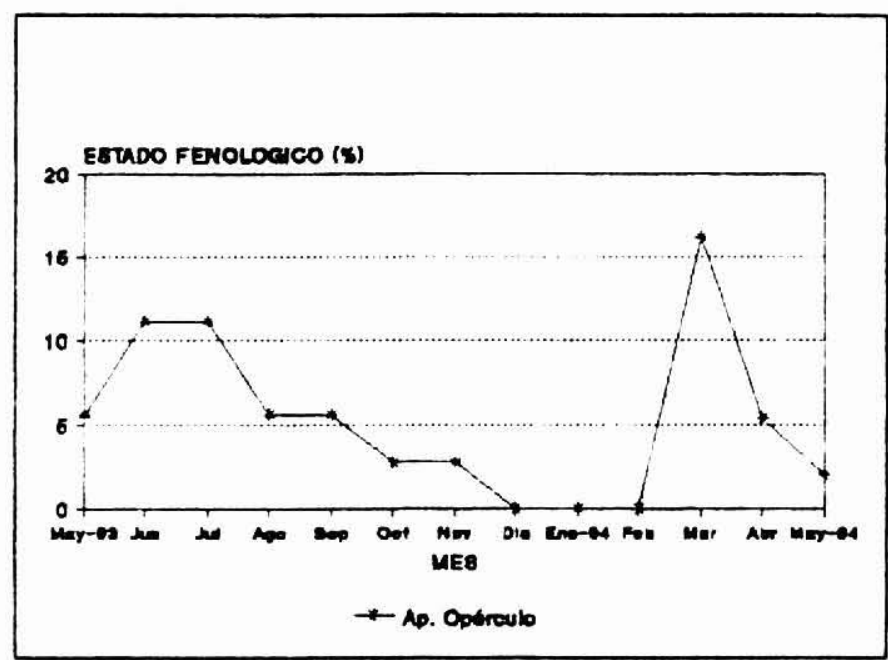

Figura $N^{\circ} 5$ a. APERTURA DEL OPERCULO EN E. nitens

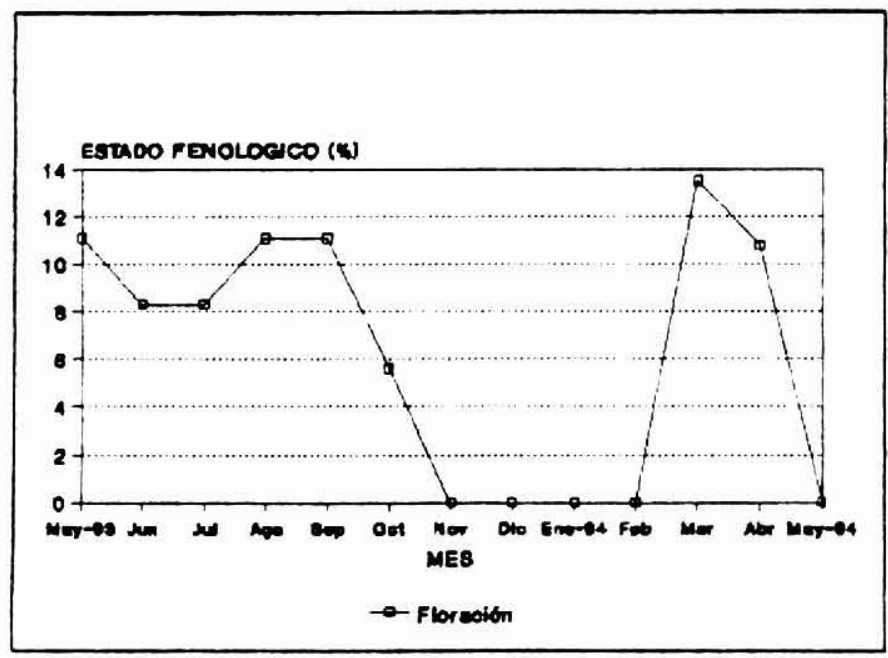

Figura $\mathrm{N}^{\circ} 5$ b. FLORACIÓN EN E. nitens 


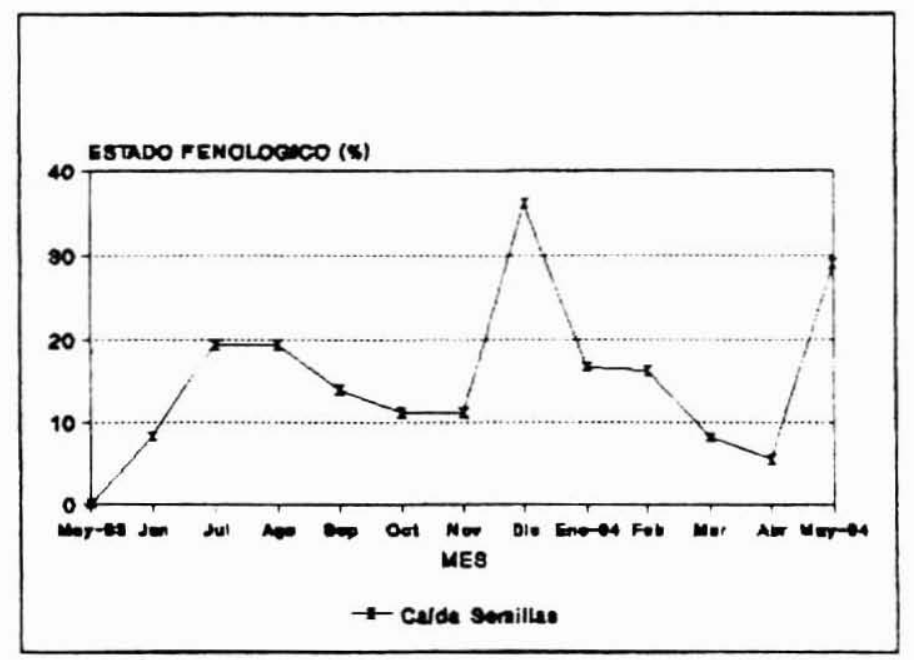

Figura No 5 C. CAIDA DE SEMILLAS $E$ nitens

\section{Cuadro $\mathrm{N}^{\circ} 4$.}

PROMEDIOS MENSUALES DE LOS ESTADOS FENOLÓGICOS POR PROCEDENCIAS DE Eucalyprus nisens., AÑo 1993

\begin{tabular}{|c|c|c|c|c|c|c|c|c|}
\hline \multirow[b]{2}{*}{ PROCED } & \multicolumn{8}{|c|}{ MESES } \\
\hline & $\begin{array}{l}\text { MAYO } \\
\mu \pm D E\end{array}$ & $\begin{array}{l}\Omega N I O \\
\mu \pm D E\end{array}$ & $\begin{array}{l}J U L I O \\
\mu \neq D E\end{array}$ & $\begin{array}{c}\text { AGOSTO } \\
\mu \approx D E\end{array}$ & $\begin{array}{c}\text { SEPT } \\
\mu \pm D E\end{array}$ & $\begin{array}{l}\text { OCTUB } \\
\mu=D E\end{array}$ & $\begin{array}{c}\text { NOV } \\
\mu \pm D E\end{array}$ & $\begin{array}{c}\text { DIC } \\
\mu \pm \text { DE }\end{array}$ \\
\hline $\begin{array}{c}\text { NSW } \\
\text { MARGEN) }\end{array}$ & $\begin{array}{l}0,50,7 \\
(6-7)\end{array}$ & $\begin{array}{l}6.81 .2 \\
(6.8)\end{array}$ & $\begin{array}{l}7.31 .1 \\
(6.8)\end{array}$ & $\begin{array}{l}8.01,4 \\
(7-9)\end{array}$ & $\begin{array}{c}7,0 \\
(7.7)\end{array}$ & $\begin{array}{c}7.0 \\
(7.7)\end{array}$ & $\begin{array}{c}7,0 \\
(7.7)\end{array}$ & $\begin{array}{c}7,0 \\
(7.7)\end{array}$ \\
\hline $\begin{array}{l}\text { VICTORIA } \\
\text { (MARGEN) }\end{array}$ & $\begin{array}{l}4,31,9 \\
(2 \cdot 7) \\
\end{array}$ & $\begin{array}{l}4,41,9 \\
(2 \cdot 7) \\
\end{array}$ & $\begin{array}{l}4,72.1 \\
(2 \cdot 7)\end{array}$ & $\begin{array}{l}5.01 .8 \\
(3.7)\end{array}$ & $\begin{array}{l}5.11,8 \\
(3-7) \\
\end{array}$ & $\begin{array}{l}5.41 .7 \\
(3.7)\end{array}$ & $\begin{array}{l}6.11 .6 \\
(3.8) \\
\end{array}$ & $\begin{array}{l}6.61,0 \\
(5-8)\end{array}$ \\
\hline PROMEDIOS & $4,71,9$ & $4,92,0$ & $5,22,1$ & $5,02.1$ & $5.31,8$ & $5,61,7$ & $6,21,5$ & $0,71,0$ \\
\hline
\end{tabular}

NSW: New South Wales.

a.b: letras diferentes en una misma columna determinan diferencias significativas ( $p<0.05$ ). 


\section{Cuadro $N^{\circ} 5$.}

\section{PROMEDIOS MENSUALES DE LOS ESTADOS FENOLÓGICOS POR PROCEDENCIAS DE Eucalyptus nitens., AN̂O 1994}

\begin{tabular}{|c|c|c|c|c|c|}
\hline & \multicolumn{5}{|c|}{ MESES } \\
\hline PROCEDENCIA & $\begin{array}{l}\text { ENERO } \\
\mu \pm \text { DE }\end{array}$ & $\begin{array}{c}\text { FEBRERO } \\
\mu \pm \mathrm{DE}\end{array}$ & $\begin{array}{l}\text { MARZO } \\
\mu \pm D E\end{array}$ & $\begin{array}{l}\text { ABRIL } \\
\mu \pm \text { DE }\end{array}$ & $\begin{array}{l}\text { MAYO } \\
\mu \pm D E\end{array}$ \\
\hline $\begin{array}{c}\text { NSW } \\
\text { MARGEN }\end{array}$ & $\begin{array}{c}7,0 \\
(7 \cdot 7)\end{array}$ & $\begin{array}{l}4,54,2 \\
(1-8)\end{array}$ & $\begin{array}{l}5.11,6 \\
(4 \cdot 7)\end{array}$ & $\begin{array}{l}4.02 .1 \\
(2-6)\end{array}$ & 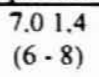 \\
\hline $\begin{array}{l}\text { VICTORIA } \\
\text { MARGEN }\end{array}$ & $\begin{array}{l}6.71 .1 \\
(4-8)\end{array}$ & $\begin{array}{l}5,42,6 \\
(1-8)\end{array}$ & $\begin{array}{l}5.91 .6 \\
(3-9)\end{array}$ & $\begin{array}{l}5.71 .9 \\
(1-8)\end{array}$ & $\begin{array}{l}7.30 .9 \\
(5-9)\end{array}$ \\
\hline PROMEDIO & 6.71 .1 & 5.22 .7 & 5.81 .5 & 5.31 .9 & $7,21,0$ \\
\hline
\end{tabular}

NSW: New South Wales.

$a, b$ : letras diferentes en una misma columna determinan diferencias significativas ( $p<0.05$ )

\section{E. camaldulensis}

El ciclo vegetativo de E. camaldulensis se mantiene activo durante todo el año. al igual que las especies anteriores.

Con respecto al ciclo reproductivo, se puede observar una gran variación en las fenofases. existiendo individuos en diferentes estados (fenofases 1 a 9) durante gran parte del año (Cuadro $\mathrm{N}^{0} 4$ ). Sin embargo, la formación de yemas florales se verifica en verano y primavera, lo que conlleva a que el periodo de floración se extienda a gran parte del año, desde agosto a enero y entre febrero y abril del año siguiente. pero con un máximo a principios del verano (Cuadro $\mathrm{N}^{\circ} 4$ ).

En este caso la liberación de las semillas se produce durante todo el año. con un máximo en el mes de agosto (Figura $\mathrm{N}^{\circ} 6 \mathrm{c}$ ).

El comportamiento fenológico a través del año en E. camaldulensis fue muy parecido al de E. globulus. difiriendo sólo en que los estados más avanzados son más marcados y permanentes. como se puede observar a partir del mes de marzo de 1994, hasta la caída de la semilla en el mes de mayo del mismo año (Figura $N^{\circ} 6 c$ ). 


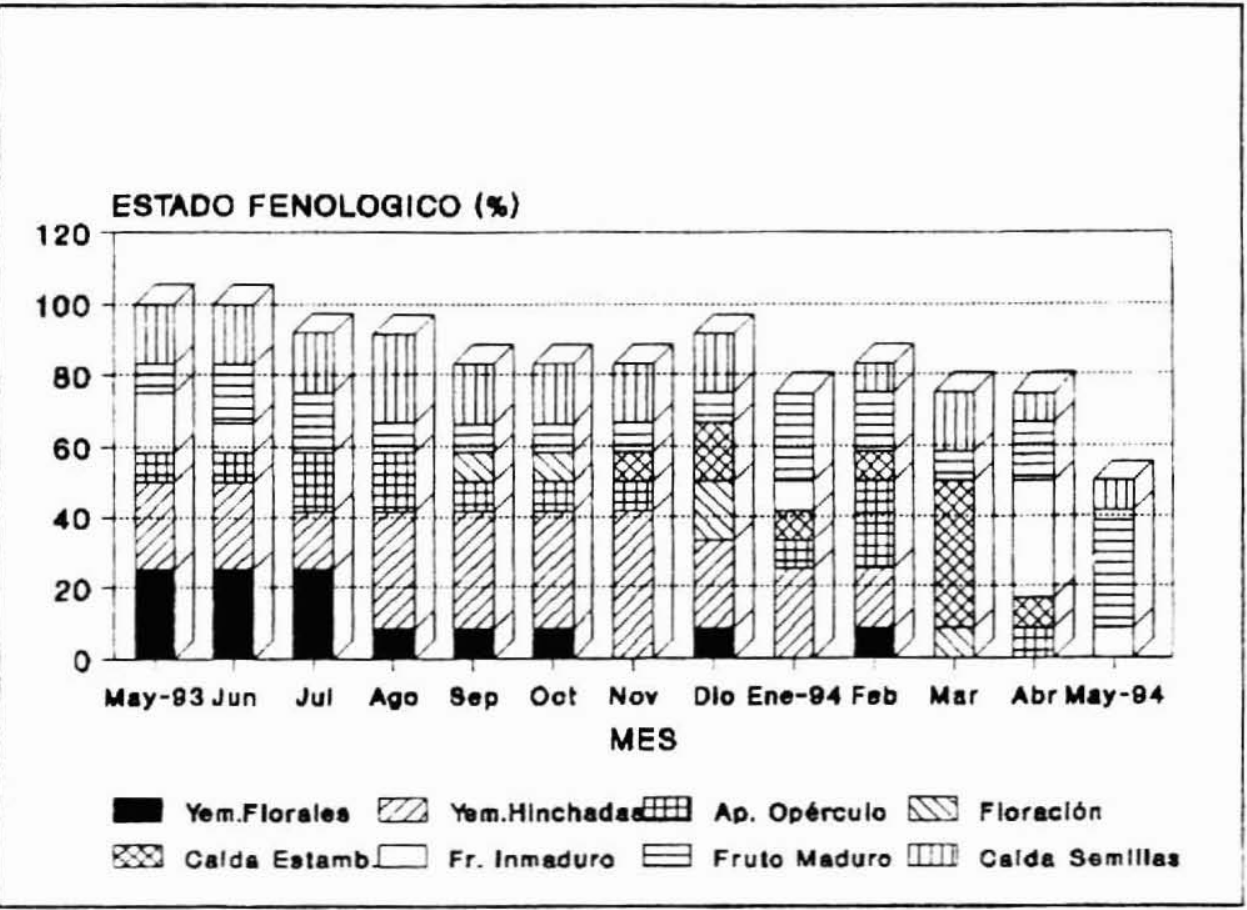

Figura $N^{\circ} 6$. COMPORTAMIENTO FENOLÓGICO E. camaldulensis

Cuadro $N^{\circ} 6$

PROMEDIOS MENSUALES DE LOS ESTADOS

FENOLÓGICOS DE Eucalỵptus camaldulensis. AÑO 1993

\begin{tabular}{|c|c|c|c|c|c|c|c|c|}
\hline & \multicolumn{8}{|c|}{ MESES } \\
\hline & $\begin{array}{l}\text { MAYO } \\
\mu \neq D E\end{array}$ & $\begin{array}{l}\pi U N I O \\
\mu=D E\end{array}$ & $\begin{array}{l}J U L I O \\
\mu=D E\end{array}$ & $\begin{array}{c}A G O S T O \\
\mu=D E\end{array}$ & $\begin{array}{c}\text { SEPT } \\
\mu \neq D E\end{array}$ & $\begin{array}{l}\text { OCTUB } \\
\mu=D E\end{array}$ & $\begin{array}{l}\text { NOV. } \\
\mu=\mathrm{DE}\end{array}$ & $\begin{array}{c}\text { DIC } \\
\mu \neq \text { DE. }\end{array}$ \\
\hline $\begin{array}{l}\text { PROMEDHO } \\
\text { (MARGEN) }\end{array}$ & $\begin{array}{l}3.92 .8 \\
(1-8)\end{array}$ & $\begin{array}{l}4.13 .0 \\
(1.91\end{array}$ & $\begin{array}{l}4,33.2 \\
(1.0)\end{array}$ & $\begin{array}{l}4,-3.1 \\
(1-9)\end{array}$ & $\begin{array}{l}4.83 .2 \\
(1-9)\end{array}$ & $\begin{array}{l}4,83,1 \\
11-0,\end{array}$ & $\begin{array}{l}4.93 .1 \\
(2-0)\end{array}$ & $\begin{array}{l}4.92 .0 \\
(2.9)\end{array}$ \\
\hline
\end{tabular}




\section{Cuadro $\mathrm{N}^{\circ} 7$}

PROMEDIOS MENSUALES DE LOS FSTADOS FENOLÓGICOS DE Eucalyprus camaldulensis. AÑO 1994

\begin{tabular}{|c|c|c|c|c|c|}
\hline & \multicolumn{5}{|c|}{ MESES } \\
\hline & $\begin{array}{c}\text { ENERO } \\
\mu \pm \mathrm{DE}\end{array}$ & $\begin{array}{c}\text { FEBRERO } \\
\mu \pm \mathrm{DE}\end{array}$ & $\begin{array}{c}\text { MARZO } \\
\mu \pm \mathrm{DE}\end{array}$ & $\begin{array}{c}\text { ABRIL } \\
\mu \pm \mathrm{DE}\end{array}$ & $\begin{array}{c}\text { MAYO } \\
\mu \pm \mathrm{DE}\end{array}$ \\
\hline PROMEDIO & $5,32.7$ & 5.32 .7 & $6,42.0$ & 7.11 .7 & 7.81 .1 \\
$($ MARGEN) & $(2-9)$ & $(2-9)$ & $(4 \cdot 9)$ & $(4-9)$ & $(6-9)$ \\
& & & & \\
\hline
\end{tabular}

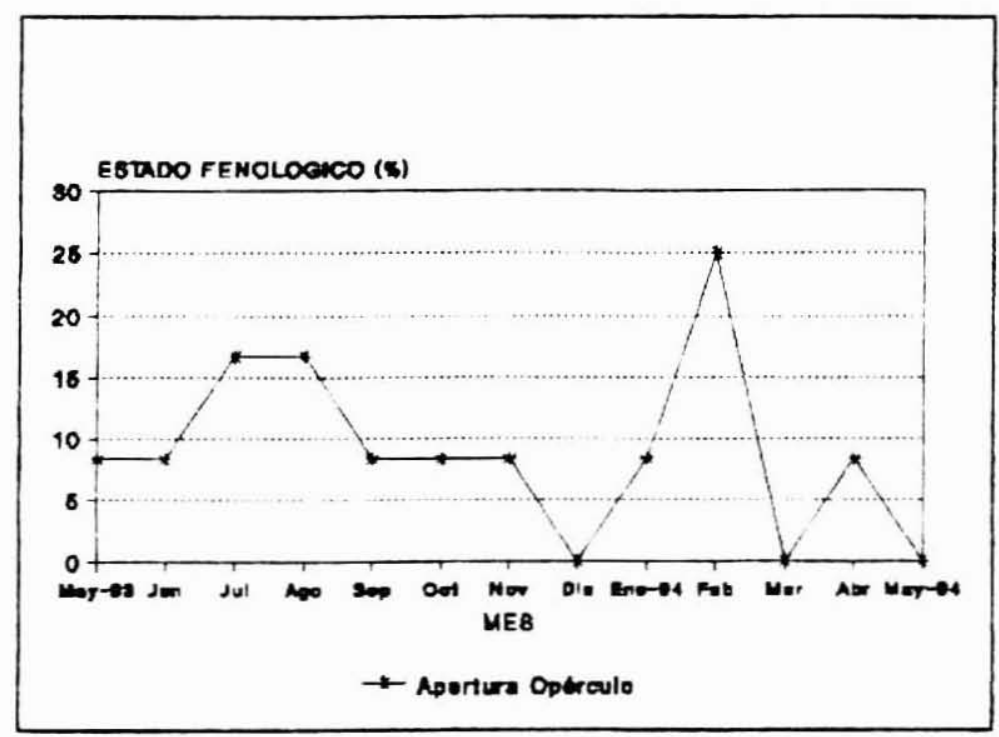

Figura $N^{\circ} 6$ a. APERTIRA DEL OPERCII,O F.N E. camaldulensis. 


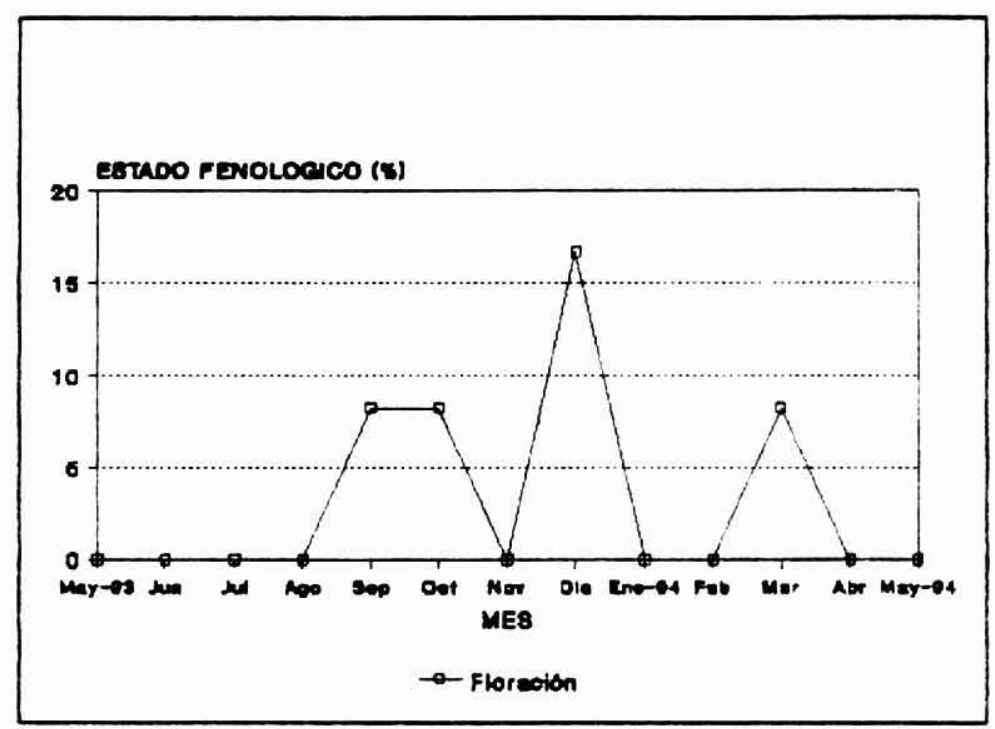

Figura $\mathrm{N}^{\circ} 6$ b. FLORACIÓN EN E. camaldulensis.

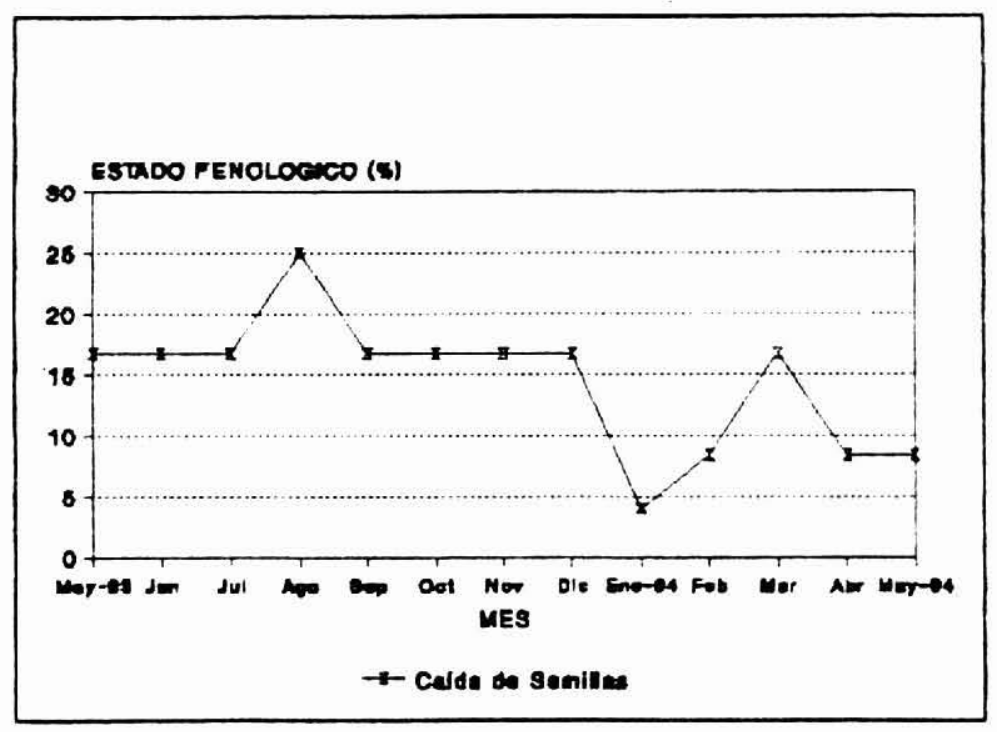

Figura $\mathrm{N}^{\circ} 6$ c. CAIDA DE SEMILLAS EN $E$. camaldulensis. 


\section{COMENTARIOS Y CONCLUSIONES}

$\mathrm{Si}$ bien el estudio presentado es de carácter preliminar y representa el comportamiento de las especies en estudio en una localidad de la zona central del país distinta de las áreas de mayor potencialidad de crecimiento de las mismas, permitió establecer parámetros de comparación y tener un conocimiento base. el que esta siendo enriquecido con las mediciones en curso en ensayos en diferentes regiones.

Resalta el hecho de que las tres especies presentan un crecimiento vegetativo sostenido durante todo el año, sin haberse observado un receso propiamente tal.

Asimismo, y como es sabido. el comportamiento fenológico de cada especie es variable de año en año, lo que refuerza la necesidad de emprender estudios de al menos tres años en las respectivas áreas de crecimiento. a fin de entregar información confiable y útil para su silvicultura y manejo.

Notoria es la estrecha relación entre condiciones climáticas dadas y respuestas fenológicas especificas. demostrando ser altamente dependientes estas últimas de las primeras.

\section{REFERENCIAS BIBLIOGRAFICAS}

Ashton, D.H. 1975a. The Seasonal Growth of E. regnans. Aust. J. of Bot. 23, 239-252

Ashton, D.H. 1975b. Studies on Flowering Behaviour in E. regnans. Aust. J. of Bot., 23: 399411 .

Boland, D.J.; Brooker, M.I.H.; Turnbull, J.W. 1980. Eucalyptus seed. CSIRO. Australia, $191 \mathrm{p}$.

Brooker, M.L.H. and Kleinig. D.A. Field Guide to Eucalyptus South-western and Southern Australia. Volumen 2: 196.

Gore, P.L; Potts, B.M.; Volker, P.W.; Megalos, J. 1990. Unilateral Cross-incompatibility in Eucalyptus: the Case of Hibridisation between E. globulus and E. nitens. Aust. J. of Bot,, 38: 383-394.

Grifnin, A.R. 1980. Floral Phenology of a Stand of Mountain Ash (E. regnans) in Gippsland, Victoria. Aust. J. of Bot. 28: 393-404.

Hodgson, LH. 1976a. Some Aspects of Flowering and Reproductive Behaviour in E. grandis at Keet Forest Research Station. 1. Flowering, Controlled Pollination Methods, Pollination and Receptivity. S. African Forestry Journal N 97.

Hodgson, L.H. 1976b. Some Aspects of Flowering and Reproductive Behaviour in E. grandis at Keet Forest Research Station. 3. Yield, Breeding Sustems, Barriers, General Conclusions. S. African Forestry Journal N 99. 
Oliveira, G.; Werner, C.; Correia, O. 1993. Influencia de la Posición de la Copa sobre la Fenologia y las Relaciones Hidricas del Alcomoque (Quercus suber). Congreso Forestal Español, Lourizan 1993. Ponencias y Comunicaciones, Tomo I: 277 - 282.

Sedgley, M. y Grimn, A.R. 1989. Sexual Reproduction of Tree Crops. Academic Press, 378 p.

Tibbits, W. 1989. Controlled Pollination Studies with Shining Gum (E. nitens). Forestry, Vol. $62 \mathrm{~N} 2$.

Urrutia, T.R.E. 1992. Caracterización y Comportamiento en Vivero de Tres Procedencias de Semillas de E. globulus Cosechadas en Chile. Tesis de grado, Universidad de Concepción, 120 p.

Valenziano, S. y Scaramuzzi, G. 1967. Osservazioni Preliminari sul Ritmo di Accrescimento in Diametro di E.camaldulensis y E. viminalis en Roma. Agric. For. Vol 9(3), 189-202.

Verkatesh, C.S. y Sharma, V.K 1975. The Flowering Phenology of Some Eucalyptus at New Forests; It's Significance and Implication in Hybridization. J. Indian Academy of Wood Sc. Vol. $2,119-121$.

\section{GLOSARIO}

Autoincompatibilidad (autoesterilidad): Se refiere a la inhabilidad de plantas fértiles para reproducirse a partir de autocruzas: inhabilidad de plantas hermafroditas fértiles a producir zigotos después de autopolinización (existe tanto prezigótica como postzigótica).

Autogamia: Fenómeno que consiste en la polinización de una flor por medio de su propio polen; como es lógico, sólo las flores hermafroditas pueden ser autógamas. Se opone a alogamia.

Cleistogamia: Fenómeno referido a las plantas cleistógamas (que poseen flores cuya polinización se produce cuando aún están cerradas).

Dicogamia: Es un mecanismo de cruzas abiertas que considera separación temporal de los sexos. donde los órganos masculinos y femeninos maduran en distintos periodos en la misma flor. Puede ser protoginea cuando la parte femenina madura antes. o protandrea, cuando la parte masculina madura antes; cuando se presentan ambos casos se denomina heterodicogamia. Las flores de muchas especies muestran algún grado de dicogamia. Los eucaliptos presentan dehiscencia de las anteras en un periodo corto después de la antesis.

Imbreeding: Cruzamiento intencional o accidental de individuos que están más cercanamente emparentados que sus progenitores.

Partenocarpia: Fenómeno por el cual se forman frutos sin previa fecundación: por consiguiente los rudimentos seminales no se transforman en semillas. o bien dan 
semillas estériles. La partenocarpia puede ser autónoma o vegetativa si se realiza sin estímulo. o bien estimulativa o etiónoma cuando se requiere cierta excitación del estigma por medio del polen (que no llega a fecundar los rudimentos seminales). o por hongos que se desarrollan en aquél como parásitos. o por otros estímulos.

Partenogénesis: Desarrollo apomíctico del óvulo. engendramiento de un individuo a partir de un óvulo no fecundado que puede ser haploide. diploide o poliploide. 